\title{
Education and training in family medicine: looking ahead
}

Pak Yean Cheong, FAMS(IM), FCFP(FM)

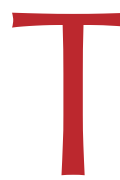

he paper by Goh and Ong ${ }^{(1)}$ offers us an opportunity to consider the healthcare landscape of Singapore from a fresh perspective, unbounded by existing constraints of established organisation, and to integrate some of the new perspectives into a rapidly changing context.

\section{VISION CHANGE}

The vision in their paper on education and training in family medicine in 2030 represents a paradigm shift, namely the shift from "primary care delivered in the community" to "family medicine as one discipline in many settings". With paradigm shifts, there will be a struggle between the incumbent and the incoming. There will also be different degrees of acceptance of the new paradigm. The shift of family medicine to "family medicine as one discipline in many settings" is no different. We are seeing it today. Why this shift is needed is elaborated on in Goh and Ong's paper.(1)

\section{UNDERSTANDING AND ADOPTING CHANGE}

At this juncture, it is useful to revisit the concept of the paradigm shift. As a premise, healthcare delivery is scientific advancement, nothing less. In 1962, Thomas Kuhn defined and popularised the concept of 'paradigm shift'.(2) Kuhn argued that scientific advancement is not evolutionary, but rather a "series of peaceful interludes punctuated by intellectually violent revolutions", and in those revolutions, "one conceptual world view is replaced by another". It does not just happen, but rather is driven by agents of change. Similarly, we do not expect the vision of a single discipline across different settings to segue logically into place. A saltatory adjustment is to be expected.

Where are we in the adoption of this new paradigm? Perhaps at the stage of knowledge progressing to persuasion, with some decision among early adopters and pockets of early implementation of the concept; for example, the Department of Family Medicine and Continuing Care in Singapore General Hospital, the Agency for Integrated Care (AIC)'s Aged Care TransiTION (ACTION) project, ${ }^{(3)}$ and AIC's Singapore Programme for Integrated Care for the Elderly (SPICE). ${ }^{(4)}$

\section{THE CASE FOR THE FAMILY MEDICINE PARADIGM SHIFT}

There is a national need for a new model to meet the healthcare needs of an older and larger population in 2030. Looking ahead three points of needed action are offered for reflection.

\section{Think systems - no man is an island}

The hold-up in healthcare delivery in Singapore and worldwide is due to the failure to think of systems in an integrated way. The famous poem by John Donne makes a plea to think systems and the sense of integration within that:

\section{No man is an island,}

Entire of itself,

Every man is a piece of the continent,

A part of the main...

... Any man's death diminishes me,

Because I am involved in mankind,

And therefore never send to know for whom the bell tolls; It tolls for thee.

Healthcare delivery as we know it in Singapore and worldwide is fragmented into levels of primary, secondary and tertiary care, each with differing notions of accountability to the patient's well-being as a whole. Clinical and financial governance is likewise fragmented. It is noteworthy that family medicine began as an attempt to reverse this fragmentation in the decades after the Second World War.

Today, there is a need to think in terms of one clinical and financial entity responsible for a discrete funding pot for a particular patient, to whom all care providers in the healthcare system are accountable. That entity managing large aggregates of such funds and commanding vertical integrated resources would best meet patients' needs within the ambit of clinical and financial governance. The well-being of the patient needs to be sovereign; the well-being of professional disciplines and their practitioners should not be the defining variable. Presently, the turfs of medical disciplines are guarded by ideology and 
tradition, and are tripping points to the unwary. In the context of America, Dr Nicholas Pisacano, who was the first Executive Director of the American Board of Family Physicians, said in 1947, "First we must do what is best for the American public. Second, we must do what is best for medicine. Finally, we must do what is best for family medicine."(5) The sovereignty of the public's needs was acknowledged. We need to uphold that patient sovereignty.

\section{Dismantling clinical silos}

With the increasing complexity of medical care, organised medicine is segregated into speciality groups based on body parts or treatment modalities. While such groupings are important for medical research and training, there is a danger of such groups of doctors demarcating silos, even for clinical care across the entire spectrum of severity. Each silo of today needs to be integrated into the rest of the healthcare landscape by some common concepts, common actions and health literacy. Clinical Practice Guidelines and care pathways are not a substitute for doctors - specialists and generalists - working in tandem and in harmony. For this to happen, the generalist healthcare givers need new rules of engagement into the integration of care. What is also assumed here is that there must be adequate training of the generalist to do the right thing, and to do it rightly all the time.

\section{Recognise the changing face of primary care}

There is a need to recognise that primary care is situation- and era-specific. In rural, remote communities, and in newly developing countries, primary care invests heavily in public health; public health doctors and nurses are the main primary care providers. As societies progress and the healthcare delivery system becomes more organised, these public health personnel give way to the family doctor or general practitioner practising ambulatory care, with whom we are familiar.

What is quietly changing in the healthcare landscape of the world and in Singapore is the growing number of older people in the population, and the varying degrees of healthcare burdens that they carry. We face an increasing number of people with healthcare needs never experienced before. Older people have increased risk of falls, and they are more likely to develop strokes and dementia, all with protracted consequences. Additionally, there are patients with advanced renal, cardiac, respiratory and other diseases, who face prolonged periods of need for support and management. We need a new way to deliver care to these people. There are too many of them to be absorbed by the hospital specialist clinics, and many are so weak or bedridden that a trip to the specialist clinic is inconceivable. Who will look after them? Is this the new primary care? What will the system of payment be like? These are addressed in the Person-Centred Medical Home papers coming out of the United States. ${ }^{(5-7)}$

With the changing landscape of healthcare delivery, primary care funding as a function of acute illness management may no longer be equitable, as additional units of time and resources will be needed to adequately deal with complex conditions. A recognition of this is needed to drive the creation of a system of funding that allows the family physician to work in less of a sweat shop, in poor regard, and financially underpowered to do the needful. America is facing a dwindling number of doctors signing up as family physicians because of inequitable returns. We have no wish to follow suit in Singapore.

\section{CONCLUSION}

This paradigm shift forces us to confront a question - do we train more to fit the disappearing present, or do we embrace the change needed and inspire a new generation aboard to train for the future?

\section{REFERENCES}

1. Goh LG, Ong CP. Education and training in Family Medicine: process and a proposed national vision for 2030, Singapore Med J 2014; 55:117-23.

2. Kuhn TS. The Structure of Scientific Revolutions. Chicago: University of Chicago Press, 1962: 10.

3. Kadir SF. Role of the multidisciplinary team in integrated care. Singapore Fam Physician 2011; 37:14-9.

4. Ho CK, Wong LM, Feng L, Huang J, Cheah J. Singapore Programme for Integrated Care for the Elderly (SPICE) - an integrated model of care to enable frail elderly to be cared for in the community. Int J Integr Care 2012; 12(Suppl3):e144.

5. Doohan NC, Duane M, Harrison B, Lesko S, DeVoe JE. The future of family medicine version 2.0: reflections from Pisacano scholars. J Am Board Fam Med 2014; 27:142-50.

6. Martin JC, Avant RF, Bowman MA, et al; Future of Family Medicine Project Leadership Committee. The future of Family Medicine: a collaborative project of the family medicine community. Ann Fam Med 2004; 2 Suppl 1:S3-32.

7. American Academy of Family Physicians, American Academy of Paediatrics, American College of Physicians, American Osteopathic Association. Joint principles of the patient-centered medical home. March 2007 [online]. Available at: http://www.acponline.org/running_practice/ delivery_and_payment_models/pcmh/demonstrations/jointprinc_05_17. pdf. Accessed January 29, 2014. 